\title{
Демин В.И., Ломоносова Д.В. \\ Обеспечение производственной безопасности на предприятиях по добыче и подготовке газа к транспорту
}

Кубанский государственный технологический университет (Россия, Краснодар)

doi:10.18411/spc-16-01-2018-13

idsp: 000001:spc-16-01-2018-13

\section{Аннотация}

Газовая промышленность - одна из важнейших отраслей экономики страны. Вопросы обеспечения взрывобезопасности, а соответственно производственного травматизма, в отрасли является актуальными.

В работе рассмотрены основные отравляющие вещества, обращающиеся на площадке установки комплексной подготовки газа (УКПГ), и основные причины утечек и выбросов их в окружающую среду. Проведена оценка вероятных последствий аварии на предприятии по добыче и подготовке газа к транспорту. Оценка производилась по величина избыточного давления ударной волны при вероятной ЧС, связанной с разгерметизацией колонны регенерации амина на расстояниях 20, 25 и 28 м до блока стабилизации конденсата. Определены класс зоны возможного разрушения, степень возможного разрушения блока стабилизации конденсата, установки водоподготовки и установки подготовки сырьевого газа, вероятность смертельного исхода человека, получения тяжелых и легких травм. Для снижения вероятности возникновения взрыва на УКПГ и снижения производственного травматизма предложены мероприятия.

Сделан вывод о том, что решение вопросов снижения производственного травматизма на предприятиях по добыче и подготовке газа к транспорту необходимо проводить комплексно путем разработки и функционирования системы управления охраной труда.

Ключевые слова: магистральный трубопровод, установка комплексной подготовки газа, производственный травматизм, риск аварии, избыточное давление ударной волны, система управления охраной труда.

Газовая промышленность - одна из важнейших отраслей экономики, которая имеет существенное значение в создании материально-технической базы страны, в связи, с чем правительство уделяет этой отрасли большое внимание. Однако добыча и транспорт газа сопряжен с рядом опасностей, одной из которых является возможность взрыва при разгерметизации оборудования. Так с 2006 по 2015 год на магистральных трубопроводах и установках произошло 545 аварий. Среднегодовой показатель аварийности составляет 50-60 аварий и в целом не имеет устойчивости к снижению. Материальный ущерб за этот период в среднем составляет 1 млн. долл. Погибло 63 человека. Более 150 человек получили травмы различной степени тяжести.

Поэтому вопрос обеспечения взрывобезопасности в отрасли является актуальным.

Подход к идентификации опасностей производственного процесса, состоянию охраны труда и производственного травматизма, оценке профессионального риска на предприятиях различного профиля рассмотрены в [1-10].

На участках комплексной подготовки газа используют установки комплексной подготовки газа (УКПГ), которые помогают подготавливать топливо для его последующей транспортировки. Очень важно соблюдать правила производственной безопасности на таких объектах, потому что они относятся к категории опасных и риск 
возникновения аварий на них выше, при этом последствия от чрезвычайных ситуаций (ЧС) могут быть весьма серьезными.

Основными отравляющими веществами (OB), обращающимися на площадке УКПГ, являются: природный газ, нестабильный конденсат, стабильный конденсат, метанол.

Основными причинами утечек и выбросов ОВ в окружающую среду являются:

- абразивный износ (эрозия) трубопроводов в первую очередь на участках технологической цепочки с обращением пластового, не очищенного в первой ступени сепарации газа;

- коррозия;

- нарушения правил эксплуатации;

- низкое качество строительно-монтажных работ,

- механические повреждения.

Природный газ, получаемый с промыслов, содержит посторонние примеси: твердые частицы (песок и окалину), конденсат тяжелых углеводородов, водяные пары и часто, сероводород и углекислый газ. Присутствие твердых частиц в газе приводит к быстрому износу соприкасающихся с газом деталей компрессоров. Твердые частицы засоряют и портят арматуру газопровода и контрольно-измерительные приборы, скапливаясь на отдельных участках газопровода, они сужают его поперечное сечение.

Жидкие частицы, оседая в пониженных участках трубопровода, также вызывают уменьшение площади его поперечного сечения. Они, кроме того, оказывают корродирующее действие на трубопровод, арматуру и приборы.

Влага в определенных условиях приводит к образованию гидратов, выпадающих в газопроводе в виде твердых кристаллов. Гидратные пробки могут полностью закупорить трубопровод.

Сероводород - весьма вредная примесь. В количествах, больших 0,01 мг на 1л воздуха рабочей зоны, он ядовит. При промышленном использовании газа содержащийся в нем сероводород отрицательно сказывается на качестве выпускаемой продукции. В присутствии влаги сероводород вызывает сильную коррозию металлов.

Очистка природного и других газов от сероводорода может осуществляться разными методами. Выбор процесса очистки природного газа от сернистых соединений в каждом конкретном случае зависит от многих факторов, основными из которых являются: состав и параметры сырьевого газа, требуемая степень очистки и область использования товарного газа, наличие и параметры энергоресурсов, отходы производства и др.

Коррозия зависит от многих факторов: от концентрации $\mathrm{H} 2 \mathrm{~S}$ и $\mathrm{CO} 2$ в очищаемом газе, степени насыщения амина кислыми газами, концентрации амина, качества поглотительного раствора, температуры технологической среды и т.д. Коррозия ускоряется под действием продуктов деградации амина, которые взаимодействуют с металлом.

Интенсивность коррозии возрастает в ряду: первичные алканоламинывторичные-третичные, так как более реакционно способные первичные и вторичные амины требуют более высоких температур для десорбции кислых газов, остаточное содержание кислых газов в регенерированных растворах таких аминов также, выше. На границе раздела фаз существенным фактором разрушения становится кавитация.

Оборудование установок очистки газа помимо общей коррозии подвергается и другому виду разрушения - коррозионному растрескиванию низколегированных и углеродистых сталей в регенерированных и насыщенных сероводородом и углекислым газом (или одним из этих газов) аминовых растворах. Вероятность растрескивания возрастает с повышением температуры. Зарегистрированы случаи появления коррозионных трещин в абсорберах, десорберах, теплообменниках, трубопроводах. 
Ещё одним видом коррозии оборудования установок сероочистки является расслоение (НIC) углеродистых и низколегированных сталей под действием водных сероводородсодержащих сред, образующихся в результате десорбции кислых газов.

При очистке газа водными растворами аминов коррозия происходит по всему тракту поглотительного раствора. Наиболее интенсивная коррозия наблюдается в зонах c максимальной концентрацией кислых газов и максимальной температурой. Следствием коррозии может стать взрыв оборудования очистки газа от серосодержащих соединений.

Вышеописанные факторы привели к тому, что в некоторых странах перешли на изготовление оборудования целиком из нержавеющей стали, несмотря на огромные первоначальные затраты. В России, как правило, основное оборудование установок очистки газа изготовляют из углеродистой стали и лишь наиболее подверженные коррозии узлы (трубные пучки теплообменников, кипятильников, холодильников) - из нержавеющей стали, скорость коррозии которой ниже, чем у углеродистой стали.

Чтобы избежать возможной катастрофы на предприятии по подготовке газа для дальнейшей транспортировки используется анализ риска аварий.

Для оценки вероятных последствий аварии на предприятии по добыче и подготовке газа к транспорту необходимо использовать Свод правил СП 12.13130.2009 «Определение категорий помещений, зданий и наружных установок по взрывопожарной и пожарной опасности», утвержденные приказом МЧС РФ от 25 марта 2009 года № 182, а именно, приложение В «Методы расчета критериев пожарной опасности наружных установок».

В работе определены величины избыточного давления ударной волны при вероятной ЧС, связанной $\mathrm{c}$ разгерметизацией колонны регенерации амина на расстояниях 20, 25 и 28 м до блока стабилизации конденсата, которые соответственно будут - 57,45 кПа, 38,89 кПа и 32,23 кПа.

Класс зоны разрушения типовых зданий и сооружений определяется по избыточному давлению ударной волны, развиваемому при сгорании газопаровоздушных смесей (таблица 1).

Таблица 1

Классификачия зон разрушения типовых зданий и оборудования

\begin{tabular}{|c|c|c|c|}
\hline $\begin{array}{c}\text { Класс зоны } \\
\text { разрушения }\end{array}$ & $\mathrm{K}$ & $\Delta P$, кПа & $\begin{array}{c}\text { Возможные последствия, характер повреждений зданий и } \\
\text { сооружений }\end{array}$ \\
\hline 1 & 3,8 & 70 & $\begin{array}{c}\text { Полное разрушение зданий с массивными стенами } \\
\text { Ризрушение стен кирпичных зданий толщиной в } 1,5 \\
\text { разрушение трубопроводных эстакад }\end{array}$ \\
\hline 2 & 5,6 & 28 & $\begin{array}{c}\text { Разрушение перекрытий промышленных зданий; } \\
\text { разрушение промышленных стальных несущих } \\
\text { конструкций; деформации трубопроводных эстакад }\end{array}$ \\
\hline 4 & 9,6 & 14 & $\begin{array}{r}\text { Разрушение перегородок и кровли зданий; повреждение } \\
\text { стальных конструкций каркасов, ферм }\end{array}$ \\
\hline 5 & 56 & $<=2$ & $\begin{array}{r}\text { Граница зоны повреждений зданий; частичное } \\
\text { повреждение остекления }\end{array}$ \\
\hline
\end{tabular}

При избыточном давлении $\Delta P$ на расстоянии, соответствующем расстояниям до блока стабилизации конденсата, установки водоподготовки и установки подготовки сырьевого газа, равным 20, 25 и 28 м, будет 3 класс зоны разрушения. Исходя из 
данного типа зданий и избыточного давления ударной волны, определяется степень разрушения производственных и административных зданий (таблица 2).

Таблиия 2

Степень разрушения производственных, административных зданий и сооружений, имеющих разную устойчивость

\begin{tabular}{|c|c|c|c|c|}
\hline \multirow{2}{*}{ Тип зданий, сооружений } & \multicolumn{4}{|c|}{$\begin{array}{c}\text { Степень разрушения при избыточном давлении на фронте } \\
\text { падающей ударной волны, кПа }\end{array}$} \\
\hline & Слабое & Среднее & Сильное & Полное \\
\hline $\begin{array}{c}\text { Промышленные здания с легким каркасом } \\
\text { и бескаркасной конструкцией }\end{array}$ & $10-25$ & $25-35$ & $35-45$ & $>45$ \\
\hline Складские кирпичные здания & $10-20$ & $20-30$ & $30-40$ & $>40$ \\
\hline $\begin{array}{c}\text { Одноэтажные складские помещения с } \\
\text { металлическим каркасом и стеновым } \\
\text { заполнением из листового металла }\end{array}$ & $5-7$ & $7-10$ & $10-15$ & $>15$ \\
\hline $\begin{array}{c}\text { Бетонные и железобетонные здания и } \\
\text { антисейсмические конструкции }\end{array}$ & $25-35$ & $80-120$ & $150-200$ & $>200$ \\
\hline $\begin{array}{c}\text { Здания железобетонные монолитные } \\
\text { повышенной этажности }\end{array}$ & $25-45$ & $45-105$ & $105-170$ & $170-215$ \\
\hline $\begin{array}{c}\text { Котельные, регуляторные станции в } \\
\text { кирпичных зданиях }\end{array}$ & $10-15$ & $15-25$ & $25-35$ & $35-45$ \\
\hline Деревянные дома & $6-8$ & $8-12$ & $12-20$ & $>20$ \\
\hline Подземные сети, трубопроводы & $400-600$ & $600-1000$ & $1000-1500$ & $>1500$ \\
\hline Трубопроводы наземные & 20 & 50 & 130 & - \\
\hline Кабельные подземные линии & до 800 & - & - & $>1500$ \\
\hline Цистерны для перевозки нефтепродуктов & $30-50$ & $50-70$ & $70-80$ & $>80$ \\
\hline Резервуары и емкости стальные наземные & $35-55$ & $55-80$ & $80-90$ & $>90$ \\
\hline Подземные резервуары & $40-75$ & $75-150$ & $150-200$ & $>200$ \\
\hline
\end{tabular}

Степень разрушения блока стабилизации конденсата, установки водоподготовки и установки подготовки сырьевого газа будет оцениваться как средняя.

№ 3 .

Условная вероятность травмирования и гибели людей определяется по таблице

Таблииза № 3

Зависимость условной вероятности поражения человека с разной степенью тяжести от степени разрушения здания

\begin{tabular}{|c|c|c|c|c|}
\hline \multirow{2}{*}{ Тяжесть поражения } & \multicolumn{4}{|c|}{ Степень разрушения } \\
\cline { 2 - 5 } & Полное & Сильное & Среднее & Слабое \\
\hline Смертельное & 0,6 & 0,49 & 0,09 & 0 \\
\hline Тяжелые травмы & 0,37 & 0,34 & 0,1 & 0 \\
\hline Легкие травмы & 0,03 & 0,17 & 0,2 & 0,05 \\
\hline
\end{tabular}


Таким образом, вероятность смертельного исхода человека будет равна 0,09 , получение тяжелых травм - 0,1 и легкие травмы - 0,2.

Для снижения вероятности возникновения взрыва на УКПГ и снижения производственного травматизма следует провести ряд мероприятий:

1. 1.Установить предохранительные устройства, такие как устройства с разрушающимися мембранами, либо импульсные предохранительные устройства (ИПУ), состоящие из главного предохранительного клапана (ГПК) и управляющего импульсного клапана (ИПК) прямого действия;

2. Увеличить количество датчиков довзрывных концентраций газа.

3. Установить запорную арматуру.

4. Установить систему непрерывного мониторинга за состоянием оборудования под давлением.

5. Использовать методы газопламенного напыления металлизационных покрытий с целью защиты от коррозии.

6. Установить систему по предупреждению образования взрывоопасной среды.

7. Установить систему автоматической противоаварийной блокировки.

8. Провести дополнительное обучение персонала.

9. Перейти на систему ремонта по состоянию оборудования, используя технические системы мониторинга.

10. Провести внеплановые инструктажи по охране труда с персоналом.

Таким образом, реализация предложенных мероприятий позволит снизить вероятность возникновения взрыва на УКПГ и производственный травматизм на предприятиях по добыче и подготовке газа к транспорту.

Решение вопросов снижения производственного травматизма на предприятиях по добыче и подготовке газа к транспорту необходимо проводить комплексно. Это возможно путем разработки и функционирования системы управления охраной труда на предприятии [10-17].

$$
* * *
$$

1. Ригер Т.В., Сапрыкина Н.В., Демин В.И., Козак Д.А. Идентификация опасностей производственного процесса на предприятиях строительной отрасли// Научные труды КубГТУ: электрон. сетевой политематич. журн. 2016. № 5. URL: http://ntk.kubstu.ru/file/953.

2. Берсекова В.И. О состоянии охраны труда в организациях строительной отрасли/ Берсекова В.И., Рыжкова А.А., Ригер Т.В., Демин В.И.// Научные труды КубГТУ: электрон. сетевой политематич. журн. 2017. № 1. URL: http://ntk.kubstu.ru/file/1328.

3. Демин В.И. Состояние производственного травматизма на малых предприятиях/ Демин В.И., Ригер Т.В., Сапрыкина Н.В./В сборнике: Природноресурсный потенциал, экология и устойчивое развитие регионов России//сборник статей XIII Международной научно-практической конференции. Под общей редакцией Селезнева В.А., Лушкина И.А. МНИЦ ПГСХА. - Пенза: РИО ПГСХА, 2015. - с. $22-25$.

4. Демин В.И., Ригер Т.В., Ломоносова Д.В. О результатах анализа производственного травматизма на предприятиях строительной отрасли//Тенденции науки и образования в современном мире, 2017. № 27-1. - c. 31-34.

5. Демин В.И., Гром Д.С. Анализ состояния электробезопасности в КубГТУ// Научные труды КубГТУ: электрон. сетевой политематич. журн. 2015. № 4. URL: http://ntk.kubstu.ru/file/376.

6. Демин В.И., Гром Д.С., Кравец А.С., Хоменко Ю.О. Оценка состояния электробезопасности на предприятиях и в организациях/В сборнике: Молодежь. Наука. Инновации//труды XIII Международной научно-практической интернет-конференции, 2016. - с. 298-308.

7. Ригер Т.В., Сапрыкина Н.В., Демин В.И., Власенко Н.В. Совершенствование работы по охране труда на предприятиях по хранению и переработке зерна// Научные труды КубГТУ: электрон. сетевой политематич. журн. 2015. № 9. URL: http://ntk.kubstu.ru/file/503.

8. Ригер Т.В. Методика оценки профессионального риска методом ис-пользования коэффициента безопасности труда/ Ригер Т.В., Сапрыкина Н.В., Демин В.И., Норман Л.В.// Научные труды КубГТУ: электрон. сетевой политематич. журн. 2016. № 5. URL: http://ntk.kubstu.ru/file/960.

9. Косова Ю.Ю., Демин В.И. Методика оценки профессионального риска электротехнического персонала/В сборнике: Разработки, достижения, творчество школьников и студентов Тульской области в различных областях знаний: доклады первой Всероссийской научно-практической 
конференции школьников и студентов Тульской области в различных областях знаний, 2011. - с. 22-24.

10. Мандаровская Ю.А., Демин В.И., Дмитренко Е.В., Ригер Т.В. Опыт организации производственного контроля в сфере охраны труда в дирекции механизированной дистанции ОАО «РЖД»// Научные труды КубГТУ: электрон. сетевой политематич. журн. 2016. № 15. URL: http://ntk.kubstu.ru/file/1303.

11. Ригер Т.В. Система управления охраной труда вуза/ Ригер Т.В., Демин В.И., Сапрыкина Н.В./В сборнике: Дальневосточная Весна-2014// сборник статей 12-й Международной научнопрактической конференции по проблемам экологии и безопасности. Под редакцией И.П. Степановой И.П., Никифоровой Г.Е. - Комсомольск-на-Амуре: ФГБОУ ВПО «КнАГТУ», 2014. - с. 120-123.

12. Демин В.И. Опыт разработки системы управления охраной труда в вузе/Демин В.И., Ригер Т.В., Сапрыкина Н.В.//В сборнике Экология и безопасность жизнедеятельности: сборник статей XIV Международной научно-практической конференции. Под общей редакцией Селезнева В.А., Лушкина И.А. МНИЦ ПГСХА. - Пенза: РИО ПГСХА, 2014. - с. 31 - 33.

13. Ригер Т.В. Разработка системы управления охраной труда на малых предприятиях пищевого профиля/ Ригер Т.В., Сапрыкина Н.В., Демин В.И., Истошина Н.Ю.// Известия высших учебных заведений. Пищевая технология, 2016. № 1. - с. 113-117.

14. Демин В.И., Ригер Т.В., Ломоносова Д.В. Особенности разработки политики в области охраны труда организации строительной отрасли// Тенденции науки и образования в современном мире, 2017. № 30-3. - с. 38-46.

15. Ригер Т.В., Демин В.И., Истошина Н.Ю., Соловьева Ж.П., Ломоносова Д.В. Опыт внедрения системы управления охраной труда на малых предприятиях пищевой промышленности.// Известия высших учебных заведений. Пищевая технология, 2016. № 5-6 (353-354). - с. 109-112.

16. Ригер Т.В. Опыт внедрения системы управления охраной труда на различных предприятиях/ Ригер T.В., Сапрыкина Н.В., Демин В.И., Власенко Н.В.// Научные труды КубГТУ: электрон. сетевой политематич. журн. 2015. № 10. URL: http://ntk.kubstu.ru/file/545.

17. Демин В.И., Аноприева И.К. Оценка рисков в учебно-курсовом комбинате ООО «УКК «Лабинский»// Тенденции науки и образования в современном мире, 2017. № 32-4. - с. 27-31.

\section{Довбыш Н.С., Фролов К.А., Жданов А.В. \\ Исследование напряженно-деформированного состояния формообразующих деталей методом конечных элементов}

Владимирский государственный университет имени Александра Григорьевича и Николая Григорьевича Столетовых (Россия, Владимир)

doi:10.18411/spc-16-01-2018-14

idsp: 000001:spc-16-01-2018-14

\section{Abstract}

The article deals with the STUDY of the stress-strain state of the DETAIL punch-die die die under the complex loading by the finite element method. The calculation was carried out for workloads for various cases of percussion of parts equivalent to wear of a die. Within the framework of the study, allowed skew angles are obtained, under which the stresses do not exceed the allowed ones.

Наиболее ответственными элементами конструкции вырубных штампов являются нагруженные формообразующие детали, которые испытывают комбинированные нагрузки. Особый интерес представляют детали вырубных штампов типа пуансон-матрица, которые находятся в сложном напряженно-деформированном состоянии (НДС), характерном как для пуансонов, так и для матриц. Традиционный подход к расчету такой детали является сильно упрощенным и не может использоваться в нашем случае. Это объясняется не только отсутствием аналитических решений для подобной геометрии, но и наличием в детали сразу нескольких существенных концентраторов напряжений. Следовательно, необходимо проводить анализ НДС данной детали с помощью численных методов. С целью оптимизации конструкции, снижения массогабаритных характеристик без изменения прочности и жесткости конструкции необходимо рассмотреть следующие вопросы: 